\title{
Seasonal Changes in Lipid and Fatty Acid Composition of the Freshwater Mollusk, Diplodom patagonicus
}

\author{
R.J. POLLERO ${ }^{1}$, R.R. BRENNER ${ }^{2}$ and E.G. GROS ${ }^{2}$, Cátedra de Bioquímica, \\ Instituto de Fisiología, Facultad de Ciencias Médicas, Universidad Nacional \\ de La Plata and Departamento de Química Orgánica, Facultad de \\ Ciencias Exactas, Fiśsicas y Naturales, Universidad de \\ Buenos Aires, Argentina
}

\begin{abstract}
Diplodom patagonicus is a freshwater bivalve mollusk living in lakes of the patagonian Andes mountains in Argentina. Lipid composition and seasonal changes in the mollusk were studied in the natural habitat. In addition to common nonpolar and polar lipids, small amounts of alk-1-enyldiacylglycerol ethers and significant quantities of ceramide aminoethyl phosphonate were present. Total lipid content changed during the year, primarily because of decreased triacylglycerols in winter. The fatty acid composition of the lipids, remarkably different from that of marine bivalves, and even from other fresh water animals, was especially rich in the $\omega 6$ fatty acids, linoleic and arachidonic (ca. 25\%), and poor in the $\omega 3$ acids, $20: 5$ and $22: 6$. The $\omega 6 / \omega 3$ acid ratio was ca. 2 , which is very high compared to marine bivalves. The fatty acid composition and the $\omega 6 / \omega 3$ acid ratio were constant during the whole year, suggesting a very stable diet, rich in vegetal detritus and poor in diatoms. The influence of environmental temperature fluctuation with season on fatty acid composition also was negligible. Modest proportions of 22:2 nonmethylene-interrupted (NMI) acids were detected and confirmed by mass spectrometry. It was shown that 20:2 NMI acids were absent.
\end{abstract}

\section{INTRODUCTION}

Diplodom patagonicus (d'Orb) is a bivalve mollusk living in lakes of the patagonian Andes. We have localized dense colonies in Lake Nahuel Huapi at depths from $3 \mathrm{~m}$ to $30 \mathrm{~m}$ or more. This is a cold-water lake poor in organic nutrients, salts and plankton. Consequently, it was important to study the lipid composition of $D$. patagonicus in its habitat and compare it to that of similar marine bivalves.

In this work, we report the lipid and fatty acid compositions of $D$. patagonicus and the changes produced during the annual cycle.

\section{EXPERIMENTAL PROCEDURES}

\section{Animals}

Specimens of $D$. patagonicus were collected by skin divers at a depth of $4 \mathrm{~m}$ in a bay of Llao-Llao peninsula of Lake Nahuel Huapi, Río Negro province, Argentina. Samples of 10 mollusks, 6 to $7.5 \mathrm{~cm}$ long, were collected in April, July, October and December and analyzed in groups of 2 .

\section{Lipid Extraction and Analysis}

Soft tissues were homogenized and the lipids extracted with chloroform/methanol $(2: 1, \mathrm{v} / \mathrm{v})$ by the Folch procedure (1), were recovered and

\footnotetext{
1 Member of the Carrera del Investigador Cientifico of the CIC Buenos Aires Province, Argentina.

2 Member of the Carrera del Investigador Cientifico of the CONICET, Argentina.
}

weighed. Polar and nonpolar lipids were fractionated by silicic acid absorption chromatography (2). Lipids of each fraction were separated by thin layer chromatography (TLC) on Silica Gel G using hexane/ethyl ether/ acetic acid (80:20:1, v/v) for nonpolar lipids and chloroform/methanol/acetic acid/water $(65: 24: 4: 4, v / v)$ for polar lipids.

Lipids were identified by comparison of $\mathbf{R}_{\mathbf{f}}$ with corresponding standards, by specific color reactions and also by additional bidimensional $\operatorname{TLC}(3,4)$. After lipid identification, routine analyses were performed by TLC on $20 \times 40$ $\mathrm{cm}$ plates. They were first developed with $\mathrm{CHCl}_{3} / \mathrm{CH}_{3} \mathrm{OH} /$ acetic acid $/ \mathrm{H}_{2} \mathrm{O} \quad(65: 25: 4: 4$, $\mathrm{v} / \mathrm{v})$ and then with hexane/ethyl ether/acetic acid $(80: 20: 1, v / v)$ in the same direction.

Quantitative estimation of the lipids was made by charring and densitometry (5).

\section{Fatty Acid Analysis}

An aliquot of the total lipids was saponified and, after extraction of the nonsaponifiables with petroleum ether, the fatty acids were esterified with $3 \mathrm{~N} \mathrm{HCl}$ in methanol. The methyl esters were analyzed by gas liquid chromatography (GLC) in a Packard apparatus at $180 \mathrm{C}$. Two liquid phases were used: $15 \%$ EGSS-X on Chromosorb WPH 80/100 mesh and $15 \%$ EGSS-Y on Chromosorb WAW $80 / 100$ mesh.

The chromatographic peaks were identified tentatively by comparison of the relative retention times $\left(R_{18: 0}\right)$ with those of standards 
measured on both columns. In addition, identifications were checked by comparison of equivalent chain length of the esters using both columns as suggested by Christie (6), and also by hydrogenation followed by GLC of hydrogenated products (7). The number of double bonds was confirmed by TLC on Silica Gel $\mathrm{H}-\mathrm{AgNO}_{3}$, followed by GLC of the separated fractions (8).

In some cases, as specified later, the identities of the fatty acids were investigated by mass spectrometry in tandem with GLC on 15\% DEGS coated on Chromosorb W. The methyl esters were injected in a Varian 1440 apparatus coupled to a Varian Mat. $\mathrm{CH}-7 \mathrm{~A}$ mass spectrometer commanded by a VarianMat. data system 166 that receives information from teletype Tektronix 4010-1. The conditions used for the ion source were: temperature $200 \mathrm{C}$, potential $70 \mathrm{eV}$, emission $1 \mathrm{~mA}$; and for the ion current detector were: temperature $200 \mathrm{C}$, potential $22 \mathrm{eV}$, emission $600 \mu \mathrm{A}$. The scanning range was 50-550 mass units while the scan speed was 19 spectra/min.

\section{RESULTS AND DISCUSSION}

\section{Lipid Composition}

The lipid composition of $D$. patagonicus, shown in Table $I$, is the result of mono- and bidimensional TLC of neutral and polar lipids and of identification reactions described later. Triacylglycerols were the main components of the neutral lipids with a mean value of $20.6 \%$ of total lipid calculated from data obtained during an en tire year.

To identify the less polar component of the chromatogram, this was recovered from the plate and chromatographed again with benzene/ hexane $(30: 70, v / v)(9)$. Two spots were found with $\mathbf{R}_{\mathbf{f}}$ values at ca. 0.5 and 1 . The spot of $\mathbf{R}_{\mathbf{f}}$ 0.5 gave a color reaction characteristic of sterols. When this fraction was saponified with $10 \% \mathrm{KOH}$ for $45 \mathrm{~min}$ and the unsaponifiables chromatographed again with benzene/hexane $(30: 70, \mathbf{v} / \mathrm{v})$, the spot with $\mathbf{R}_{\mathbf{f}} \cong 1$ remained unmodified. This was attributed to hydrocarbons, whereas the spot of $R_{f} 0.5$ disappeared, demonstrating that it corresponded to sterol esters. Also, this result verified the absence of waxes.

Free and esterified sterols also were recognized in the thin layer chromatograms of neutral lipids by color reaction with sulfuric acid/acetic acid (50:50, v/v). The spot with $R_{f}$ 0.13 , which maintained its position after saponification and gave a color reaction characteristic of sterols, was eluted from the silica gel and resolved by TLC with hexane/ethyl ether/ methanol/acetic acid $(90: 50: 5: 2, \mathrm{v} / \mathrm{v})$ into free sterols and diacylglycerols.

The existence of alk-1-enyl diacylglycerol ethers was recognized in the spot $\left(R_{f} \quad 0.67\right)$ found near the triacylglycerols, by reaction with 2,4-dinitrophenyl hydrazine. A spot with an $R_{f}$ of 0.20 , coincident with linoleylol, was attributed to aliphatic alcohols. Small amounts of pigments might be present in the monoacylglycerol spot and therefore they may be less than the values shown in Table $I$.

Phospholipids present in the mollusks are shown in Table I. In addition to the common phospholipids, a spot of $R_{f} 0.40$, a little higher than that of phosphatidylcholine (PC), was attributed to a ceramide-aminoethyl phosphonate since it gave positive reactions with ninhydrin and chlorobenzidine. This phospholipid has been recognized in other mollusks $(10,11)$ and sea anemones (12).

TABLE I

Lipid Composition of $D$. patagonicus a

\begin{tabular}{|c|c|c|c|}
\hline Nonpolar & Distribution (\%) ${ }^{\mathbf{b}}$ & Polar & Distribution (\%) \\
\hline \multicolumn{4}{|l|}{$\begin{array}{l}\text { Hydrocarbons }+ \\
\text { esterified sterols }\end{array}$} \\
\hline Diacylglycerol ethers & $5.5(0-11.1)$ & $\begin{array}{l}\text { Ceramide aminoethyl } \\
\text { phosphonate }\end{array}$ & \\
\hline \multirow{2}{*}{$\begin{array}{l}\text { Triacylgiycerols } \\
\text { Fatty acids }\end{array}$} & $20.6(12.0-27.0)$ & Phosphatidylcholine & $21.1(18.4-24.8)$ \\
\hline & $1.0 \quad(t-4.0)$ & & \\
\hline Fatty alcohols & $0.8 \quad(t-1.1)$ & Sphingomyelin & $4.6(2.9-8.1)$ \\
\hline $\begin{array}{l}\text { Free sterols } \\
\text { Diacylglycerols }\end{array}$ & $14.2(11.3-18.0)$ & Lysophosphatides & $(\mathrm{t}-3.7)$ \\
\hline Monoacylglycerols & $3.4(2.7-6.0)$ & & \\
\hline
\end{tabular}

${ }^{a}$ The lipids were separated by TLC on Silica Gel G; neutral lipids with hexane/ether/acetic acid (80:20:1, $\mathrm{v} / \mathrm{v})$ and polar lipids with $\mathrm{CHCl}_{3} / \mathrm{CH}_{3} \mathrm{OH} /$ acetic acid/ $\mathrm{H}_{2} \mathrm{O}(65: 25: 4: 4, \mathrm{v} / \mathrm{v})$.

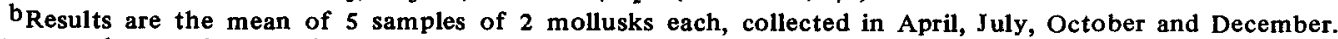
Extreme values are in parentheses. 


\section{Seasonal Changes of the Lipids}

The lipid content of $D$. patagonicus changes during the year; the lowest value $(0.62 \% \pm$ $0.05 \mathrm{SE}$, expressed with reference to wet weight of soft tissues) was found in winter (July) and the highest $(1.45 \% \pm 0.13 \mathrm{SE})$ in spring (end of October) (Fig. 1). This change includes the triacylglycerol content which decreases from $24.1 \%$ in autumn (April) to approximately half this value $(12.6 \%)$ in winter (July). The highest value $(27 \%)$ was found in spring.

The main function of triacylglycerols is energy storage and, as they generally increase with an enhanced food intake, these results would indicate that, in the spring, there is an increase in food consumption. In addition, an increased triacylglycerol in this period might indicate a prespawning conditioning of the animal, whereas the decrease in December might correspond to an expulsion of sexual elements.

The seasonal change in the phospholipids was very small (Fig. 1). These lipids are constituents of membranes and lipoproteins and, therefore, they are not subjected to the changes found with depot fats which are involved in storage and consumption of energy.

\section{Fatty Acid Composition}

The fatty acid composition of $D$. patagonicus is illustrated in Table II. The type of fatty acids found corresponds, in general, to an aquatic pattern since the longer chain $\omega 3$ acids, $20: 5$ and $22: 6$, are present, but the quantitative composition shows that palmitic, linoleic, eicosenoic and arachidonic acids are the main components. The high content of $\omega 6$ acids, linoleic and arachidonic (ca. 25\% of all acids), and low amounts of $\omega 3$ acids found during the entire year are remarkable. The structure of both $\omega 6$ acids was determined by the GLC methods already indicated and, in addition, by mass spectrometry. This assignment of structure for $20: 4 \omega 6$ was confirmed by comparing to the mass spectra of a standard sample.

Fatty acids of the $\omega 6$ family are typical of land animals feeding preferentially on linoleicacid-containing plants. Therefore, $D$. patagonicus shows a characteristic fatty acid composition with a very high $\omega 6 / \omega 3$ acid ratio that makes it different from even other freshwater animals and shows a certain similarity to land animals (13).

Paradis and Ackman (14) have shown that nonmethylene-interrupted (NMI) fatty acids, $20: 2$ and $22: 2$, may be found in mollusks. For this reason, a search for those fatty acids was
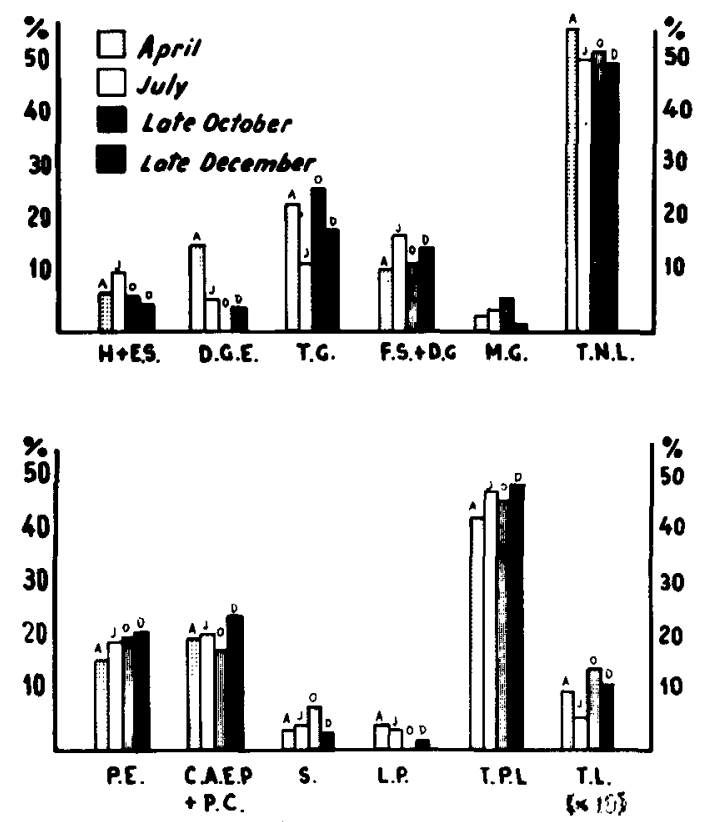

FIG. 1. Seasonal variation in lipid composition of D. patagonicus. $\mathrm{H}$ : hydrocarbons; E.S.: esterified sterol; D.G.E.: diacylglyceryl ethers; T.G.: triacylglycerols; F.S.: free sterols; D.G.: diacylglycerols; M.G.: monoacylglycerols; T.N.L.: total neutral lipids; P.E.: phosphatidylethanolamine; C.A.E.P.: ceramide aminoethylphosphonate; S: sphingomyelin; L.P.: lysophospholipids; T.P.L.: total polar lipids; T.L.: total lipids.

made. In particular, the large peak attributed to a 20:1 methyl ester was investigated, since it could include NMI 20:2 acids. When the sample was chromatographed on EGSS-X, the retention time of this peak corresponded to $18: 3 \omega 3$ and $20: 1$ methyl esters. Both components were resolved by GLC on EGSS-Y, showing that the 20:1 ester was the predominant fatty acid ester. In addition, the mass spectrum (Fig. 2) of the peak separated by GLC on $15 \%$ DEGS produced a molecular ion of 324 , corresponding to $20: 1$ methyl ester, but no molecular ion of 322 could be detected. Therefore, we concluded that NMI 20:2 esters were not present in this peak.

The presence of NMI 22:2 acids also was investigated by mass spectrometry of the peak with $R_{18: 0}=4.18$ on the EGSS-X column. The mass spectrum (272) is shown in Figure 3. The chromatographic peak corresponding to spectrum 272 is tentatively identified as a $22: 2$ methyl ester. It shows a molecular ion $\left(\mathrm{M}^{+}\right)$ of 350 and a base peak of $82\left(\mathrm{C}_{6} \mathrm{H}_{10}\right)$. The main fragmentation in the high range indicates the loss of 31 and 32 (methanol) mass units, 
TABLE II

Seasonal Variation (\%) in Fatty Acid Composition of D. patagonicus ${ }^{a}$

\begin{tabular}{|c|c|c|c|c|}
\hline Fatty acid & $\begin{array}{l}\text { Autumn } \\
\text { (April) }\end{array}$ & $\begin{array}{l}\text { Winter } \\
\text { (July) }\end{array}$ & $\begin{array}{c}\text { Spring } \\
\text { (late Oct.) }\end{array}$ & $\begin{array}{c}\text { Summer } \\
\text { (late Dec.) }\end{array}$ \\
\hline $\begin{array}{l}14: 0 \\
15: 0+X_{1} \\
16: 0 \\
16: 1 \\
17: 0+X_{2} \\
18: 0 \\
18: 1 \\
18: 2 \omega 6 \\
18: 3 \omega 6 \\
20: 1+18: 3 \omega 3^{b} \\
18: 4 \omega 3 \\
20: 3 \\
20: 4 \omega 6+22: 1^{c} \\
22: 2+20: 4 \omega 3^{d}(N M I) \\
20: 5 \omega 3 \\
X_{3} \\
22: 4 \omega 6 \\
22: 4 \omega 3 \\
22: 5 \omega 3 \\
22: 6 \omega 3 \\
\text { Environmental } \\
\text { temperature (C) }\end{array}$ & $\begin{array}{r}3.6 \pm 0.3 \\
1.9 \pm 0.2 \\
17.6 \pm 2.3 \\
3.8 \pm 0.8 \\
2.4 \pm 0.2 \\
8.6 \pm 0.9 \\
5.3 \pm 0.4 \\
8.8 \pm 0.6 \\
\text { trace } \\
10.8 \pm 1.7 \\
1.2 \pm 0.5 \\
0.5 \pm 0.2 \\
17.2 \pm 2.8 \\
6.3 \pm 0.5 \\
2.7 \pm 0.7 \\
1.6 \pm 0.3 \\
2.7 \pm 0.3 \\
2.7 \pm 0.6 \\
0.7 \pm 0.3 \\
1.6 \pm 0.1\end{array}$ & $\begin{aligned} & 7.0 \pm 1.7 \\
& 1.0 \pm 0.4 \\
& 22.3 \pm 0.5 \\
& 3.3 \pm 0.2 \\
&- \\
& 6.2 \pm 0.3 \\
& 5.0 \pm 0.2 \\
& 11.3 \pm 0.4 \\
& \text { trace } \\
& 12.6 \pm 0.1 \\
& 1.3 \pm 0.2 \\
& 0.7 \pm 0.0 \\
& 13.6 \pm 1.0 \\
& 5.9 \pm 0.1 \\
& 3.5 \pm 0.3 \\
& 1.8 \pm 0.1 \\
& 2.1 \pm 0.1 \\
& 1.1 \pm 0.1 \\
& 0.5 \pm 0.1 \\
& 0.8 \pm 0.1\end{aligned}$ & $\begin{array}{c}8.6 \pm 0.5 \\
\text { trace } \\
27.5 \pm 0.5 \\
5.8 \pm 0.4 \\
\text { trace } \\
5.0 \pm 0.3 \\
5.0 \pm 0.2 \\
9.8 \pm 0.5 \\
- \\
10.7 \pm 0.2 \\
1.3 \pm 0.1 \\
\text { trace } \\
13.7 \pm 0.6 \\
4.6 \pm 0.2 \\
2.5 \pm 0.3 \\
1.0 \pm 0.1 \\
1.6 \pm 0.1 \\
1.2 \pm 0.0 \\
0.5 \pm 0.1 \\
1.2 \pm 0.1\end{array}$ & $\begin{aligned} 7.0 & \pm 1.3 \\
\text { trace } & \\
18.8 & \pm 0.6 \\
7.1 & \pm 0.2 \\
& \\
6.5 & \pm 0.4 \\
7.4 & \pm 0.3 \\
10.7 & \pm 0.3 \\
& - \\
11.1 & \pm 0.3 \\
1.9 & \pm 0.1 \\
\text { trace } & 12.9 \pm 0.9 \\
5.2 & \pm 0.2 \\
3.5 & \pm 0.2 \\
1.6 & \pm 0.1 \\
2.4 & \pm 0.1 \\
1.8 & \pm 0.2 \\
0.6 & \pm 0.1 \\
1.5 & \pm 0.1\end{aligned}$ \\
\hline
\end{tabular}

aThe composition was calculated from gas liquid chromatogram on $15 \%$ EGSS-X (Chromosorb WHP) at $180 \mathrm{C}$. Results are the mean of 5 samples \pm standard error.

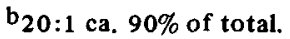

$c_{20: 4 \omega 6} \mathrm{ca} .80 \%$ of total.

$d_{22: 2}$ ca. $80 \%$ of total.

producing ions at $\mathrm{m} / \mathrm{e} 319(\mathrm{M}-31)$ and 318 (M-32), respectively. The lower mass region is heavily populated with hydrocarbon ions which are of little use for structural purposes. Because of double-bond migration at the molecular ion stage, the location of the double bonds cannot be firmly established.

As a tentative approach, ions at $\mathrm{m} / \mathrm{e} 150$ and 96 could indicate a $\Delta 7, \Delta 14$ structure whereas

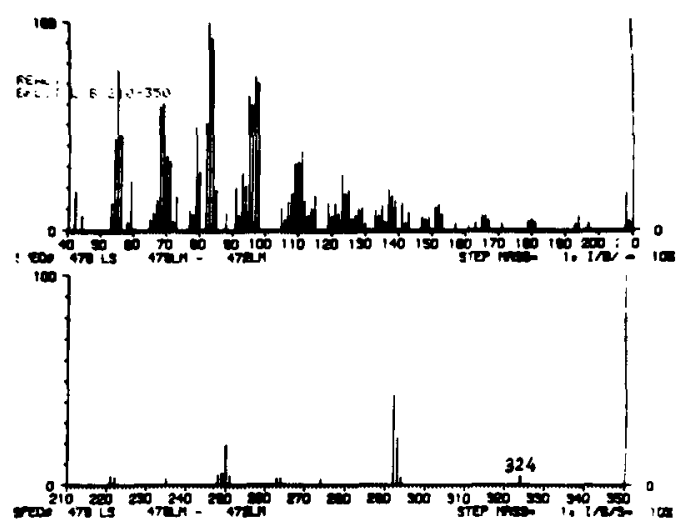

FIG. 2. Mass spectrum of gas liquid chromatographic peak identified as $20: 1$ acid methyl ester. those ions at $\mathrm{m} / \mathrm{e} 96$ and 82 would point to a $\Delta 7, \Delta 13$ structure.

At present, because of the lack of standard spectra, it is not possible to determine the correct structure by this method.

The origin of this acid or acids is still open for dicussion and cannot be deduced from the current data. They might be derived from the diet, but we cannot discard the possibility that

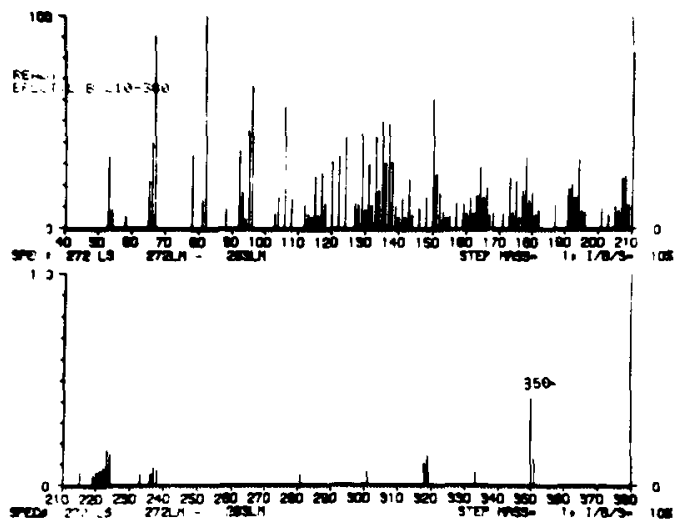

FIG. 3. Mass spectrum of gas liquid chromatographic peak identified as NMI $22: 2$ acid methyl ester. 
they may be synthesized from traces of NMI $20: 2$ acid by elongation or from a 20:1 by desaturation and elongation.

\section{Seasonal Changes of the Fatty Acid Composition}

The fatty acid composition of $D$. patagonicus changes very little during the year (Table II). It would depend on 2 main factors: its food (amount and composition) and the cellular biosynthetic and catabolic activities. The 2 main food elements of filtering animals even as mollusks are plankton and plant detritus.

Generally, aquatic systems show phytoplanktonic "blooms," one of which generally occurs in spring, due to an increase in daylight, temperature and other factors provided there are enough nutrients for rapid cell multiplication of the algae. However, in Lake Nahuel Huapi, the temperature and concentration of nutrients is low and no phytoplanktonic "blooms" have been detected (S. Guarrera, private communications). Therefore, this observation and the stable seasonal fatty acid composition of $D$. patagonicus (Table II) would indicate a rather constant food composition and no seasonal change in biosynthetic activity.

Diatoms are the predominant phytoplanktonic species of Lake Nahuel Huapi and have been found in $D$. patagonicus. They generally are rich in 20:5 $\omega 3$ acid (15). However, the fatty acid composition of $D$. patagonicus is very poor in both $20: 5 \omega 3$ and $22: 6 \omega 3$ acids. An increase of these acids would be expected in the mollusk if a "bloom" of diatoms had occurred, as has been demonstrated in other organisms $(16,17)$. Therefore, it is probable that diatoms do not comprise the main food of $D$. patagonicus.

Linoleic and arachidonic acids constitute ca. $25 \%$ of all fatty acids during the entire year. Therefore, we may deduce that the diet probably is very rich in vegetation but that it is not necessarily of planktonic origin. This deduction is supported by the presence of abundant plant detritus in the habitat of D. patagonicus. The fatty acid composition of this detritus was very rich in linoleic acid (proportions commonly around $24 \%$ ). Arachidonic acid probably could be biosynthesized in the mollusk from linoleic acid provided by the plants.
Seasonal changes of water temperature in a lake depend on, e.g., the depth, currents, winds, sunlight and hour. Temperature is quite variable in the surface water but constant in deep water. In the colony studied, it was different at depths of $4 \mathrm{~m}$ and $30 \mathrm{~m}$. The samples analyzed were collected at $4 \mathrm{~m}$ and an extreme change of 7.5 C (6-13.5 C) was measured during the year. However, in spite of this difference, no special adaptation to this temperature change was shown in the fatty acid composition of the mollusk. We have found similar results in marine mollusks $(11,16,17)$.

\section{ACKNOWLEDGMENTS}

This research has been supported by grants from the Scientific Commission of the Buenos Aires Province and the SECYT, Argentina.

\section{REFERENCES}

1. Folch, J., M. Lees and G.H. Sloane-Stanley, J. Biol. Chem. 226:497 (1957).

2. Wren, J.J., J. Chromatogr. 4:173 (1960)

3. Christie, W.W., in "Lipid Analysis," Pergamon Press, Oxford, 1973, p. 168.

4. Christie, W.W., in "Lipid Analysis," Pergamon Press, Oxford, 1973, p. 196.

5. Blank, M.L., J.A. Schmit and O.S. Privett, J. Am. Oil Chem. Soc. 41:371 (1964).

6. Christie, W.W., in "Lipid Analysis," Pergamon Press, Oxford, 1973, p. 108.

7. Farquhar, J.W., W. Insull, P. Rosen, W. Stoffel and R.H. Ahrens, Nutr. Rev. 17:29, Suppl, 8 Part II, (1959).

8. Dudler, P.A., and R.E. Anderson, Lipids 10:113 (1975).

9. Withers, N.W., and J.C. Nevenzel, Lipids $12: 989$ (1 977).

10. Hosi, T., O. Itasak and H. Inoni, J. Biochem. 59:570 (1966).

11. de Moreno, J.E., V. Moreno and R.R. Brenner, Lipids $11: 334$ (1976).

12. Mason, W.T., Biochim. Biophys. Acta 280:538 (1972).

13. Sargent, J.R., in "Biochemical and Biophysical Perspectives in Marine Biology, Vol. 3, 1976, p. 200.

14. Paradis, M., and R.G. Ackman, Lipids 12:170 (1977).

15. Kates, M., and B.E. Volcani, Biochim. Biophys. Acta 116:264 (1966).

16. Pollero, R.J., M.E. Ré and R.R. Brenner, Comp. Biochem. Physiol. 64:257 (1979).

17. de Moreno, J.E.A., R.J. Pollero, V. Moreno and R.R. Brenner, J. Exp. Mar. Biol. Ecol. (in press).

[Received May 19, 1980] 